\title{
OPEN Azolla incorporation under flooding reduces grain cadmium accumulation by decreasing soil redox potential
}

\author{
Chen Liu ${ }^{1}$, Bin Guo ${ }^{1}$, Hua Li ${ }^{1}$, Qinglin $\mathrm{Fu}^{1}$, Ningyu $\mathrm{Li}^{1}$, Yicheng $\mathrm{Lin}^{1 \bowtie}$ \& Guozhong $\mathrm{Xu}^{2}$
}

Cadmium (Cd) presents severe risks to human health and environments. The present study proposed a green option to reduce bioavailable $\mathrm{Cd}$. Rice pot experiments were conducted under continuous flooding with three treatments (T1: intercropping azolla with rice; T2: incorporating azolla into soil before rice transplantation; CK: no azolla). The results showed that azolla incorporation reduced soluble $\mathrm{Cd}$ by $37 \%$ compared with the CK treatment, which may be explained by the decreased soil redox potential (Eh) $(r=0.867, P<0.01)$. The higher relative abundance of Methylobacter observed in azolla incorporation treatment may account for dissolved organic carbon increase $(r=0.694 ; P<0.05)$, and hence decreased the $\mathrm{Cd}$ availability for rice. Azolla incorporation increased the abundance of Nitrospira, indicating the potentially prominent role of nitrogen mineralization in increasing rice yields. Further, lower soluble Cd decreased the expression of OsNramp5, but increased OsHMA3 levels in rice roots, which decreased $\mathrm{Cd}$ accumulation in grains. Through these effects, azolla incorporation decreased $\mathrm{Cd}$ concentrations in rice grains by $80.3 \%$ and increased the production by $13.4 \%$. The negligible amount of $\mathrm{Cd}$ absorbed by azolla would not increase the risk of long-term application. Thus, intercropping azolla with early rice and incorporating azolla into soil before late rice transplantation can contribute to safe production at large scales of double rice cultivation.

Rice (Oryza sativa L.) is the most widely consumed staple food in China and other countries in Asia. However, it has a high absorptive efficiency for cadmium (Cd), which has led to high dietary Cd intake and poses serious threats to human health ${ }^{1-3}$. Various chemical and biological approaches have been proposed to control Cd uptake by rice plants in paddy fields ${ }^{4}$, such as lime, phosphate compounds, metal oxides and organic matter (OM) amendment ${ }^{5,6}$. However, these methods are still limited in practice, especially at large scales because of cultivation customs, regional disparities, costs, and potential secondary pollution risks. Therefore, a viable approach to decrease Cd bioavailability with cost-efficient and undisturbed cultivation habits still needs to be explored.

It is well documented that the soil redox potential (Eh) is the key factor in controlling Cd solubility and bioavailability ${ }^{7,8}$. In general, Eh has been controlled by water management. Under flooding, the Eh was approximately $-200 \mathrm{mV}$ which leads to reducing. Furthermore, dissolved Cd declines and is transformed into Cd-sulfide (CdS) or iron-manganese (oxyhydro) oxides with low solubility ${ }^{9,10}$. It has been widely accepted that Cd accumulation in rice increases during the heading and maturing stages, and is accompanied by a higher Eh caused by drainage $\mathrm{e}^{11,12}$.

In a previous experiment, we found that the process of azolla incorporation could significantly decrease soil Eh after submergence. We hypothesized that the azolla incorporation could decrease Cd phytoavailability by regulating Eh. In addition, as a type of $\mathrm{OM}$, azolla decomposition may reduce $\mathrm{Cd}$ mobility by forming complexes without increasing Cd bioavailability ${ }^{6,13}$. However, to our knowledge, few investigations have been conducted to study the remediation effects of azolla incorporation.

Soil bacterial community are highly sensitive to soil $\mathrm{Eh}^{14,15}$. Soil microbes affect plant metal accessibility through their involvement in the decomposition, stabilization and maintenance of soil physical and chemical conditions, such as Proteobacteria and Acidobacteria ${ }^{16,17}$. In addition, microbial community composition affectes plant growth and Cd accumulation by complex interactions ${ }^{18}$. Therefore, it is essential to clarify the effect of

${ }^{1}$ Institute of Environment, Resource, Soil and Fertilizer, Zhejiang Academy of Agricultural Sciences, Hangzhou 310021, China. ${ }^{2}$ Agricultural Ecology Institute, Fujian Academy of Agricultural Sciences, Fuzhou 350003, China. ${ }^{\square}$ email: lyc5918@sina.com 


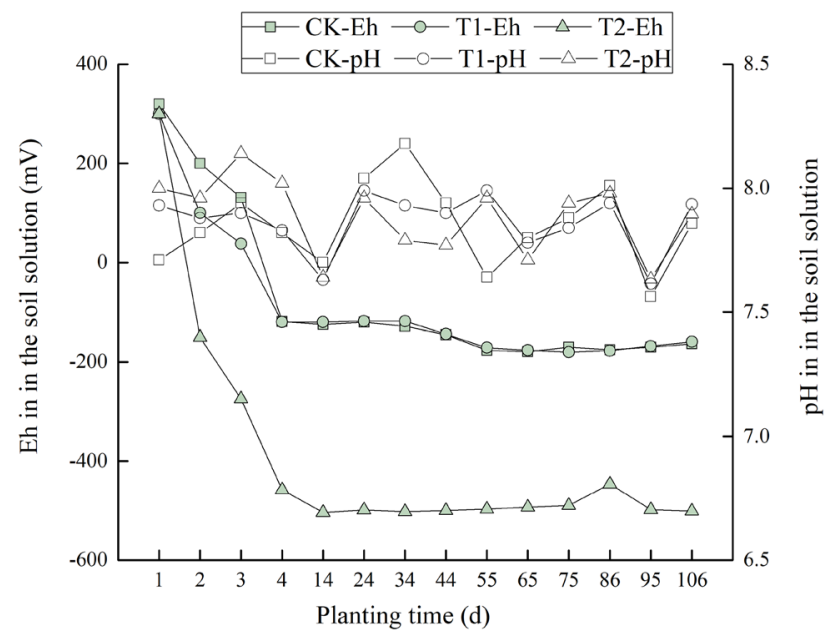

Figure 1. Changes in soil Eh and $\mathrm{pH}$ among different treatments. Treatments: no azolla (CK), azolla culturing in the water layer and intercropping with rice (T1), azolla incorporated into soil before rice transplantation (T2).

\begin{tabular}{|c|c|c|c|}
\hline Planting time (d) & Treatment & $\mathrm{Cd} /\left(\mu \mathrm{g} \mathrm{L}^{-1}\right)$ & $\mathrm{SO}_{4}^{2-} /\left(\mathrm{mg} \mathrm{L}^{-1}\right)$ \\
\hline \multirow{3}{*}{2} & CK & $0.20 \pm 0.03 \mathrm{a}$ & $790 \pm 76.8 \mathrm{a}$ \\
\hline & T1 & $0.17 \pm 0.01 \mathrm{a}$ & $722 \pm 133 a$ \\
\hline & $\mathrm{T} 2$ & $0.18 \pm 0.02 \mathrm{a}$ & $359 \pm 104 \mathrm{~b}$ \\
\hline \multirow{3}{*}{$\begin{array}{l}35 \\
\text { tillering stage }\end{array}$} & $\mathrm{CK}$ & $0.17 \pm 0.02 \mathrm{a}$ & $572 \pm 108 \mathrm{a}$ \\
\hline & $\mathrm{T} 1$ & $0.16 \pm 0.03 \mathrm{a}$ & $626 \pm 145 a$ \\
\hline & $\mathrm{T} 2$ & $0.11 \pm 0.01 \mathrm{~b}$ & $156 \pm 73.7 \mathrm{~b}$ \\
\hline \multirow{3}{*}{$\begin{array}{l}106 \\
\text { maturing stage }\end{array}$} & CK & $0.16 \pm 0.02 \mathrm{a}$ & $454 \pm 99.1 \mathrm{a}$ \\
\hline & $\mathrm{T} 1$ & $0.14 \pm 0.01 \mathrm{a}$ & $448 \pm 104 \mathrm{a}$ \\
\hline & T2 & $0.10 \pm 0.01 \mathrm{~b}$ & $123 \pm 57.4 \mathrm{~b}$ \\
\hline
\end{tabular}

Table 1. Changes in $\mathrm{Cd}$ and $\mathrm{SO}_{4}{ }^{2-}$ concentrations in soil solutions at different growth stages. Treatments: no azolla (CK), azolla culturing in the water layer and intercropping with rice (T1), azolla incorporated into soil before rice transplantation (T2). Different letters represented significant difference at $P<0.05$.

azolla incorporation on soil bacterial communities, which may in turn accelerate the reduction process and lead to ripple effects on Cd mobility.

Furthermore, the final grain Cd concentration of is controlled by several key processes, such as absorption by roots via OsNramp5, and root to shoot translocation by xylem via OsHMA3 ${ }^{19-21}$. The gene expression of specific rice varieties is certain, and soil Cd mobility in soil may affect efficiency. For example, decreased OsNramp5 levels and increased OsHMA3 levels were present in upland rice/ Solanum nigrum intercropping systems, which induced lower DTPA-Cd concentrations ${ }^{22}$. It is not clear whether the reduced Cd uptake is caused by changing Cd transporters levels in rice, or by reducing the availability of soil Cd due to incorporation of a sculpted bacterial community.

Therefore, this study aimed to investigate the effects of azolla incorporation on plant growth, Cd accumulation, soil parameters and bacterial change in the rhizosphere, and the gene expression of related Cd transporters in rice under flooding. We hypothesized that the azolla incorporation (i) decreases rhizosphere Eh and soluble $\mathrm{Cd}$, and changes the soil bacterial community, thereby decreasing Cd availability for rice; and (ii) decreases Cd concentration in various rice parts by downregulating $\mathrm{Cd}$ transporter genes in the roots and enhancing biomass. Our findings provide a green approach for reducing cadmium accumulation in rice, that can be applied at large-scales.

\section{Results}

$\mathrm{Eh}, \mathrm{pH}$, and $\mathrm{Cd}$ and $\mathrm{SO}_{4}{ }^{2-}$ concentration of soil solution. Soil Eh differed with the status of azolla (Fig. 1). With azolla incorporation (T2), Eh decreased significantly from 300 to $-274 \mathrm{mV}$ in the first $2 \mathrm{~d}$ and then remained stable at approximately $-500 \mathrm{mV}$. The soil Eh of CK decreased from 300 to $131 \mathrm{mV}$ in the first 2 $\mathrm{d}$, which was slower than that of $\mathrm{T} 2$. The Eh of the azolla intercropping treatment (T1) remained approximately $-170 \mathrm{mV}$, which was similar to that of CK. During the growth period, $\mathrm{pH}$ values fluctuated between 7.7 and 8.1. There were no significant $\mathrm{pH}$ differences among all treatments.

As shown in Table 1, the Cd concentrations in soil solutions of the azolla incorporation treatment (T2) were $0.11 \mu \mathrm{g} \mathrm{L}-1$ and $0.10 \mu \mathrm{g} \mathrm{L}^{-1}$ at the tillering and maturing stages, respectively, which were significantly lower than 


\begin{tabular}{|l|l|l|l|l|l|l|}
\hline Treatment & $\mathbf{S O C} /\left(\mathbf{m g ~ k g}^{-1}\right)$ & $\mathrm{TOC} /\left(\mathrm{g} \mathrm{kg}^{-1}\right)$ & $\mathrm{NH}_{4}{ }^{+}-\mathbf{N} /\left(\mathbf{m g ~ k g}^{-1}\right)$ & $\mathrm{NO}_{3}{ }^{-} \mathrm{N} /\left(\mathbf{m g ~ k g}^{-1}\right)$ & $\mathrm{TN} /\left(\mathrm{g} \mathrm{kg}^{-1}\right)$ & $\left.\mathrm{CaCl}_{2}-\mathrm{Cd}^{-} / \mathbf{m g ~ k g}^{-1}\right)$ \\
\hline CK & $33.3 \pm 12.4 \mathrm{~b}$ & $10.2 \pm 0.23 \mathrm{a}$ & $3.46 \pm 0.22 \mathrm{~b}$ & $2.19 \pm 0.27 \mathrm{~b}$ & $1.76 \pm 0.03 \mathrm{a}$ & $188 \pm 8.13 \mathrm{a}$ \\
\hline T1 & $40.3 \pm 7.97 \mathrm{~b}$ & $10.4 \pm 0.09 \mathrm{a}$ & $3.19 \pm 0.09 \mathrm{~b}$ & $1.84 \pm 0.14 \mathrm{~b}$ & $1.80 \pm 0.09 \mathrm{a}$ & $198 \pm 5.09 \mathrm{a}$ \\
\hline T2 & $74.5 \pm 4.04 \mathrm{a}$ & $10.4 \pm 0.31 \mathrm{a}$ & $4.12 \pm 0.42 \mathrm{a}$ & $2.83 \pm 0.39 \mathrm{a}$ & $1.80 \pm 0.09 \mathrm{a}$ & $144 \pm 11.4 \mathrm{~b}$ \\
\hline
\end{tabular}

Table 2. Soil physicochemical properties under different treatments. Different letters represented significant difference at $P<0.05$.

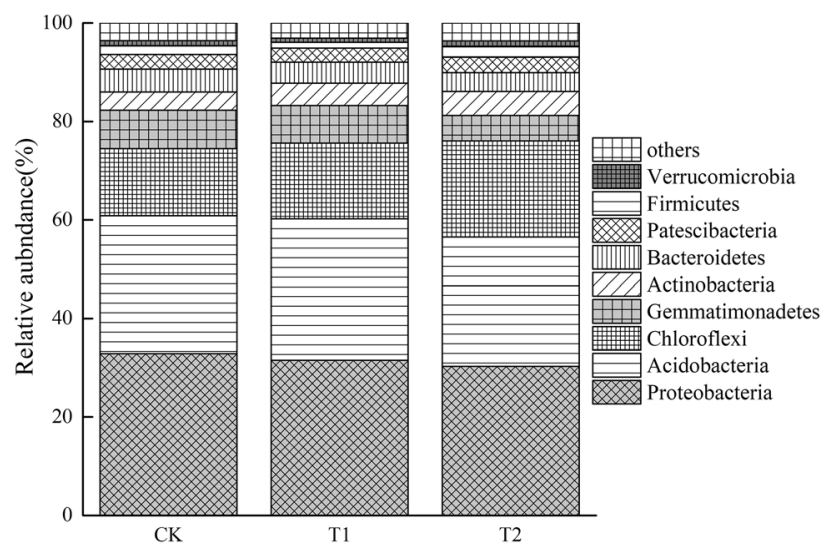

Figure 2. Relative abundances ( $>1 \%)$ of different bacterial phyla.

those of CK. There were no differences in Cd concentrations between the CK and azolla intercropping treatments (T1). Compared with the CK treatment, azolla incorporation treatment (T2) decreased $\mathrm{SO}_{4}{ }^{2-}$ concentrations in the soil solutions by $54.5-72.9 \%$. The $\mathrm{SO}_{4}{ }^{2-}$ concentrations in soil solution of the azolla intercropping treatment (T1) were similar to those of the CK treatment.

Soil chemical properties. As shown in Table 2, azolla incorporation treatment (T2) significantly increased SOC, $\mathrm{NH}_{4}{ }^{+}-\mathrm{N}$ and $\mathrm{NO}_{3}{ }^{-} \mathrm{N}$. Total nitrogen and total carbon were similar among all treatments. Compared with the CK treatment, azolla incorporation treatment (T2) decreased available $\mathrm{Cd}\left(-\mathrm{CaCl}_{2}\right)$ by $23.7 \%$. There was a significant correlation between soluble $\mathrm{Cd}$ and available $\mathrm{Cd}(r=0.784, P<0.01)$.

Soil bacterial community. The bacterial community diversity indices are shown in Table S1. There were no significant differences in the Chao1, Simpson, Shannon indexes or in Good's coverage.

Eight dominant phyla (relative abundance $>1 \%)$ included Proteobacteria $(\sim 32 \%)$, Acidobacteria $(\sim 28 \%)$, Chloroflexi ( 16\%), Gemmatimonadetes ( 7\%), Actinobacteria, Bacteroidetes, Patescibacteria, Firmicutes, and Verrucomicrobia (Fig. 2). The ranked order of these phyla was similar across all treatments, except for Chloroflexi and Gemmatimonadetes. Compared with the CK treatment, azolla incorporation increased the relative abundances of Chloroflexi by $43.4 \%$ but decreased the relative abundances of Gemmatimonadetes by $33.7 \%$.

Redundancy analysis (RDA) explained $70.2 \%$ of the variance, and it appears that azolla incorporation affected the structure of the soil bacterial community (Fig. 3). The azolla incorporation treatment (T2) had a close relationship with the relative abundances of Chloroflexi, and the CK treatment had a close relationship with the relative abundances of Gemmatimonadetes. Among all environmental variables, Cd concentration in soil solution was the most important factor influencing rhizosphere bacterial communities $(P<0.05)$. According to the results of correlation analysis, the relative abundances of Chloroflexi had a significant negative correlation with the $\mathrm{Eh}$, and $\mathrm{SO}_{4}{ }^{2-}, \mathrm{Cd}$ concentrations in the soil solutions $(r=-0.688, r=-0.623, r=-0.726 ; P<0.05$, respectively), while the relative abundances of Gemmatimonadetes had a significant positive correlation $(r=0.754, r=0.699$, $r=0.751 ; P<0.05$, respectively).

The 50 most abundant genus of the 12 samples indicated a clear difference in bacterial community structure among all treatments (Fig. 4). Azolla incorporation resulted in lower abundances of Haliangium (Proteobacteria), Gemmatimonas (Gemmatimonadetes), and Flavisolibacter (Bacteroidia), which have a positive relationship with soil Cd and Eh (Table S2). The relative abundances of Methylobacter (Gammaproteobacteria) and Nitrospira (Nitrospirae) were higher in the azolla the azolla incorporation treatment (T2) and had positive correlations with dissolve organic carbon (DOC), $\mathrm{NH}_{4}{ }^{+}-\mathrm{N}$ and $\mathrm{NO}_{3}{ }^{-} \mathrm{N}$.

Relative expression of OsNramp5 and OsHMA3 in roots. Compared with the CK treatment, the relative expression of OsNramp5 in roots was significantly lower in the azolla incorporation treatment (T2), in which the $\mathrm{Cd}$ concentration were lower in roots (Fig. 5). In addition, the expression level of OsNramp5 was correlated with the total Cd content in roots $(r=0.81, P<0.01)$. Compared with the CK treatment, azolla incor- 


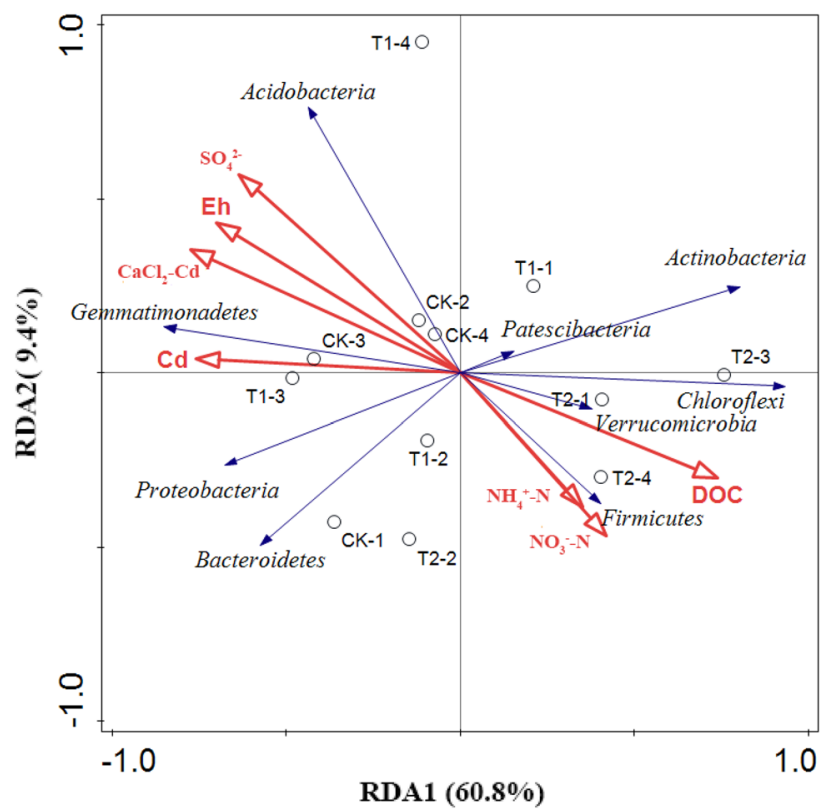

Figure 3. RDA between soil parameters and soil bacterial structure at the phylum level.

poration treatment (T2) upregulated OsHMA3 expression, which resulted in less Cd accumulation in grains. The translocation factor was also lower with the azolla incorporation treatment (T2) than with the CK treatment. The expression levels of OsHMA3 were significantly negatively correlated with TF' $(r=-0.75, P<0.01)$.

Cd concentration in rice and azolla. Under alone flooding (CK) without azolla, the Cd accumulations in roots, straw and grains were $14.6,1.07$ and $0.46 \mathrm{mg} \mathrm{kg}^{-1}$, respectively (Table 3). The Cd concentrations in roots with the azolla incorporation treatment (T2) decreased significantly by $49.8 \%$ compared with the CK treatment. Furthermore, Cd concentrations in grains of the azolla incorporation treatment (T2) were only $0.09 \mathrm{mg} \mathrm{kg}^{-1}$, which were lower than those of CK $\left(0.46 \mathrm{mg} \mathrm{kg}^{-1}\right)$. Cd concentrations in grains were similar between $\mathrm{T} 1$ and $\mathrm{CK}$, which were consistent with the results of similar Eh and Cd concentrations in the soil solutions. Cd concentrations in roots, straw and grains were positively correlated with Cd concentrations in soil solutions (roots: $r=0.90$; straw: $r=0.78$; grains: $r=0.89$; $P<0.01$ ). Compared with the CK treatment, azolla incorporation decreased the TF' by $56.4 \%$, which indicated lower Cd transport from roots to shoots due to the decreased amount of Cd absorption by roots. The Cd concentration and content of azolla in azolla intercropping treatment (T1) were $0.90 \mathrm{mg} \mathrm{kg}^{-1}$ and $4.84 \mu \mathrm{g} \mathrm{pot}^{-1}$, respectively, which were much lower than those in rice (30.2-69.6 $\left.\mu \mathrm{g}\right)$ (Table S3). Owing to the low $\mathrm{Cd}$ content of azolla, azolla incorporation process would not increase soil Cd bioavailability.

The azolla incorporation treatment enhanced the growth of rice. Compared with the CK treatment, the dry mass of roots, straw and grains increased by $18.7 \%, 12.1 \%$ and $13.4 \%$, respectively (Fig. 6).

\section{Discussion}

In recent years, many in-situ stabilization techniques have been tested on Cd-contaminated paddy soils to reduce uptake by rice ${ }^{5}$. In our study, azolla incorporation led to a significant decrease in soil soluble Cd, which may be due to decreased Eh and $\mathrm{SO}_{4}{ }^{2-}$ concentrations $(r=0.83$ and $r=0.88$, respectively; $P<0.01)$. Previous studies have verified that $\mathrm{Cd}$ mobility could decrease at lower Eh levels ${ }^{8,23}$. Since sulfate reduction occurs under reducing situations, poorly soluble CdS is formed, which results in a reduced Cd mobility ${ }^{10,24,25}$. As Eh increased, sulfate concentrations in soil solutions increased by oxidizing sulfur, and forming soluble $\mathrm{CdSO}_{4}{ }^{26,27}$. Another possible explanation is that when incorporated into soil, a considerable amount of organic $\mathrm{C}$ can be supplied, which significantly increase soil DOC levels. The increased levels of DOC and solid organic matter could decrease Cd phytoavailability by forming complex and increasing surface charge $e^{6,13}$. Increased OM may also enhance sulfate reduction and decrease $\mathrm{Cd}$ mobility ${ }^{28}$. In general, soil $\mathrm{pH}$ is an important factor that affects Cd phytoavailability with negative correlation ${ }^{6,29}$. In our present study, $\mathrm{pH}$ levels increased from 5.8 to approximately 8.0 once flooded. However, $\mathrm{pH}$ values were similar among treatments, which were inconsistent with Cd concentrations in the soil solutions. Thus, $\mathrm{pH}$ is not the main reason to account for the lower soluble Cd level in azolla incorporation treatment.

At the phylum level, the orders of primary bacteria and microbial a diversity in the rhizosphere soils of all treatments were similar ${ }^{15,30}$. This is likely due to community readjustment, as some metal-sensitive bacteria increase, and some resistant bacteria decrease as $\mathrm{Cd}$ concentrations change. In our study, azolla incorporation treatment decreased the relative abundance of Gemmatimonadetes. An et al. reported that Gemmatimonadetes was higher in contaminated soil with a high tolerance to Cd stress ${ }^{31}$. At genus level, Flavisolibacter (Bacteroidetes) was higher in the CK treatment with higher Cd concentration. A previous study also reported that Cd can stimulate the abundance of Flavisolibacter, which could catalyze hydrogen peroxide under high Cd contamination ${ }^{32}$. 
Specific species involved in Cd immobilization were modified after azolla incorporation. It has been reported that increased abundances of Chloroflexi were involved in immobilizing soil $\mathrm{Cd}^{33}$. Chloroflexi are photosynthetic bacteria that affect the stability of microflora/fauna communities by involving the cycling of iron and manganese $\mathrm{e}^{34}$.

As a kind of methane-oxidizing bacteria, Methylobacter (Gammaproteobacteria) prefers oxygen-deficient conditions and attributes to anaerobic oxidation of methane with interconnection between denitrifiers and iron-cycling partners ${ }^{35}$. In our study, the higher relative abundance of Methylobacter in azolla incorporation treatment is positively correlated with DOC $(r=0.694, P<0.05)$. Studies confirmed that organic residues addition significantly increased the soil methane production potentials and DOC level ${ }^{36,37}$. Straw input could also stimulate soil nitrite oxidizing potential by affecting the relative abundance of Nitrospira, which is reported to be a major players in nitrite oxidation ${ }^{38,39}$. Incorporating azolla into soil could increase rice yield and soil fertility by providing additional $\mathrm{N}$ nutrient ${ }^{40}$. This could explain why azolla incorporation treatment $(\mathrm{T} 2)$ had the higher content of available $\mathrm{N}$, which were beneficial to increase yields.

In our study, the low Cd bioavailability with azolla incorporation induced decreased root-to-shoot translocation. Zhang et al. also demonstrated that root-to-shoot translocation of Cd decreased under flooding ${ }^{14}$. These results were also confirmed by the gene expression results of OsNramp5 and OsHMA3. Downregulation of OsNramp5 suppressed Cd transport from soil solutions into root cells, which reduced root Cd accumulation ${ }^{41}$. Upregulated OsHMA3 could reduce shoot Cd accumulation but sequester more Cd in root cells ${ }^{19,42}$. Possible mechanism is that lower $\mathrm{Cd}$ concentrations in the rhizosphere directly trigger and regulate the expression of related genes in rice roots. For example, compared with monoculture, decreased OsNramp5 levels and increased OsHMA3 expression were present in upland rice/Solanum nigrum intercropping systems, which induced lower DTPA-Cd concentrations ${ }^{22}$. Similar results were found by Chen et al. ${ }^{43}$.

$\mathrm{Cd}$ concentrations in rice were similar between $\mathrm{T} 1$ and CK, which confirmed that azolla intercropping did not influence Cd accumulation in rice. Compared with the single flooding control, Cd concentrations in rice (roots, straw, and grains) declined dramatically by $49.8-295 \%$ with azolla incorporation. Notably, Cd concentrations in grains were lower than the Chinese national standard of $0.20 \mathrm{mg} \mathrm{kg}^{-1}$ under such high soil Cd contamination levels $\left(1.12 \mathrm{mg} \mathrm{kg}^{-1}\right)$. The results indicated that incorporating azolla into soil could dramatically decrease Cd accumulations in rice. This effect is even better than that of limestone, a popular practice that decreases Cd in grains $\left(\sim 0.3 \mathrm{mg} \mathrm{kg}^{-1}\right)$ without affecting yield under similar contamination levels ${ }^{44}$. Total Cd concentration and bioavailable Cd fractions of organic amendments determined the long-term effects on Cd immobilization. Cd concentration in the soil surface and water layer is 4-6 times lower than in deep soil solution, the Cd absorbed by azolla was negligible (Table S2). This unique characteristic makes it as a 'clean' OM, different from straw or other green manure. Thus, azolla incorporation under flooding can be recommended as a practical method to control Cd bioavailability at large scales of double rice cultivation.

\section{Conclusions and prospects}

In the present study, we proposed azolla incorporation combined with water management as a green approach to decrease Cd accumulation in rice grains. Soluble Cd decrease was achieved because of greater Eh decrease. Less phytoavailable Cd could be caused by the higher relative abundance of Methylobacter that involved in carbon mineralization. Additionally, azolla incorporation increased the relative abundance of Nitrospira and affected the $\mathrm{N}$ dynamics. Decreasing Cd bioavailability reduces the translocation and accumulation of Cd in grains by changing the expression of OsNramp5 and OsHMA3. Taken together, azolla incorporation result in a Cd accumulation reduction in grains. This finding provided a feasible and economical strategy to meet the requirements of $\mathrm{Cd}$ reduction and production promotion, which could be widely used at large-scale polluted double rice fields. Azolla is intercropped with early rice as a dual crop and then incorporated into soil before late rice transplanting. It should be noted that the effects are practical-dependents. Further field experiments under multi season are also needed.

\section{Materials and methods}

Soil properties and pot experiment.. Paddy soil for the pot experiment was collected from Linan (China), which has a textural composition of $52 \%$ sand, $30 \%$ silt and $18 \%$ clay. The parent material of this soil was fluvial deposits. Soil organic carbon (SOC) and total nitrogen (TN) content were $9.87 \mathrm{~g} \mathrm{~kg}^{-1} \mathrm{and}_{1.32} \mathrm{~g} \mathrm{~kg}^{-1}$, respectively. Total $\mathrm{Cd}$ and $0.1 \mathrm{M} \mathrm{CaCl}_{2}$-extractable $\mathrm{Cd}$ concentrations were 1.12 and $0.31 \mathrm{mg} \mathrm{kg}^{-1}$, respectively. Soil $\mathrm{pH}$ was 5.80 (1:2.5 soil/water). CEC was $15.28 \mathrm{cmol} \mathrm{kg}$. Each treatment consisted of four replicated pots each containing $10 \mathrm{~kg}$ of soil and with mixing fertilizers $(\mathrm{N}, \mathrm{P}$ and $\mathrm{K})$ at $0.5 \mathrm{~g} \mathrm{pot}^{-1}$. Urea $\left(0.2 \mathrm{~g} \mathrm{pot}^{-1}\right)$ was topdressed at 10 and $60 \mathrm{~d}$ after transplantation.

The treatments included (1) no azolla as the control, CK; (2) $50 \mathrm{~g}$ of fresh azolla (Azolla caroliniana willd, provided by Agricultural Ecology Institute, Fujian Academy of Agricultural Sciences) cultured in the water layer, intercropping with rice, T1; and (3) $200 \mathrm{~g}$ of fresh azolla incorporated before rice cultivation, incorporated into soil before rice transplanting, T2 (Fig. S1). After propagating for about 10 days, the amount of azolla in treatment T1 was about $200 \mathrm{~g}$. Total carbon and nitrogen of azolla were $41.5 \%$ and $2.64 \%$, respectively. All pot was flooded during the entire rice growth season with at least a $3 \mathrm{~cm}$ water layer on the soil surface. If the water layer fell below the minimum limit, we irrigated gently to avoid disturbing the soil layer.

Rice seeds (Oryza sativa L. cv. ZheFuJing83) were sterilized with 5\% sodium hypochlorite for $15 \mathrm{~min}$ and washed extensively with sterilized water. These seeds were then incubated at $30{ }^{\circ} \mathrm{C}$ for $48 \mathrm{~h}$ in darkness and were geminated in wetted filter paper at $35^{\circ} \mathrm{C}$ for an additional $24 \mathrm{~h}$. Finally, uniformly germinated seeds were selected and transferred to pots after four weeks. Each pot contained three plants. Plants were grown in a greenhouse and was irrigated with tap water. Rice was transplanted on July 17 and harvest on October 30. 

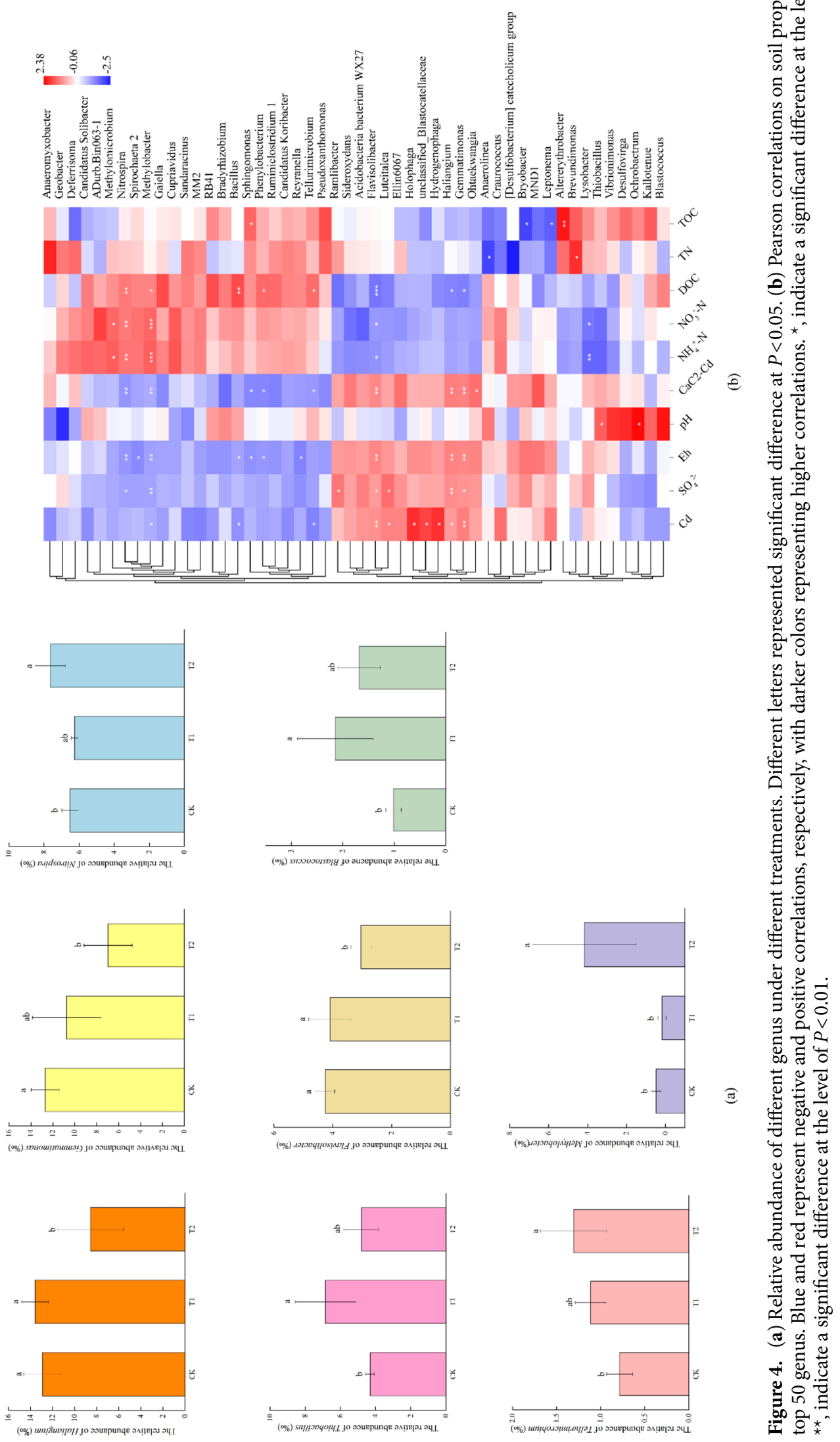


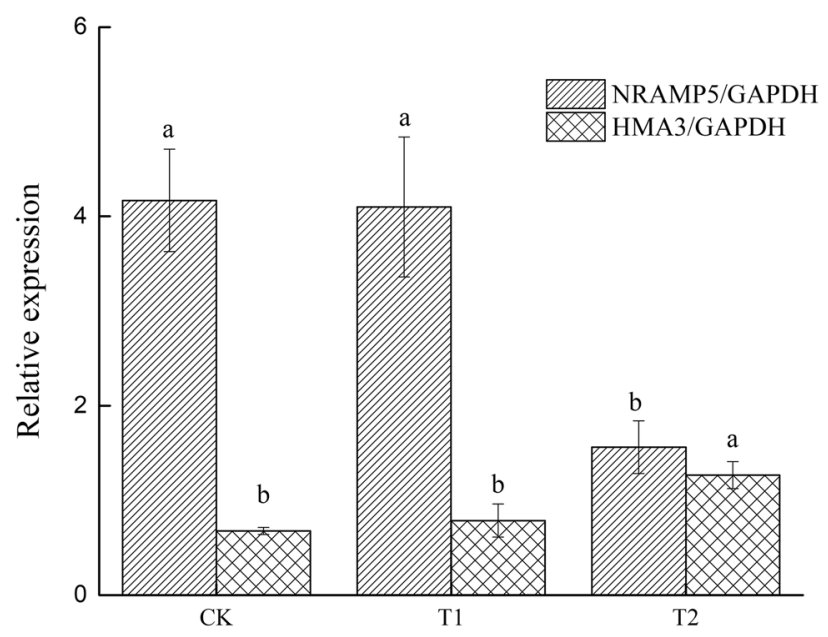

Figure 5. Relative expression of OsNramp5 and OsHMA3 genes in roots. Different letters represented significant difference at $P<0.05$.

\begin{tabular}{|c|c|c|c|c|}
\hline \multirow[b]{2}{*}{ Treatment } & Grains & Straw & Roots & \multirow[b]{2}{*}{ TF' } \\
\hline & \multicolumn{3}{|c|}{ Cd concentration $/ \mathrm{mg} \mathrm{L}^{-1}$} & \\
\hline $\mathrm{CK}$ & $0.46 \pm 0.03 \mathrm{a}$ & $1.07 \pm 0.10 \mathrm{a}$ & $14.6 \pm 2.70 \mathrm{a}$ & $0.78 \pm 0.19 a$ \\
\hline T1 & $0.40 \pm 0.08 \mathrm{a}$ & $1.29 \pm 0.23 \mathrm{a}$ & $14.3 \pm 0.91 \mathrm{a}$ & $0.82 \pm 0.16 \mathrm{a}$ \\
\hline $\mathrm{T} 2$ & $0.09 \pm 0.04 \mathrm{c}$ & $0.27 \pm 0.08 \mathrm{~b}$ & $7.35 \pm 0.92 b$ & $0.34 \pm 0.08 \mathrm{~b}$ \\
\hline
\end{tabular}

Table 3. Cd concentrations in the roots, straw and grains of rice and its translocation factor from roots to shoots. Different letters represented significant difference at $P<0.05$.

Sampling. Soil Eh was measured at $10 \mathrm{~cm}$ beneath the soil surface using an Eh meter and platinum electrodes in each pot. Soil $\mathrm{pH}$ was also measured in situ with a pH electrode. Except for the first $3 \mathrm{~d}$, soil Eh and $\mathrm{pH}$ values were recorded at $10 \mathrm{~d}$ intervals. A clay pot end soil solution extractor (suction-cup method) was adopted for in-situ sampling. It was inserted in each plot into the $10 \mathrm{~cm}$ soil layer before transplantation. When sampling, water in the tube was drained in advance, and $20 \mathrm{~mL}$ of soil solution was then extracted by a syringe $1 \mathrm{~h}$ later.

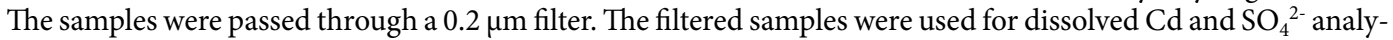
sis. At the maturing stage (October 30 ), roots, straw and grains were separated and air-dried for analysis. Soil samples, that tightly adhered to the rice roots were collected to determine soil chemical properties and bacterial community structures.

Chemical analyses. For biomass measurements, each part of the rice plant was washed and dried (at 105 ${ }^{\circ} \mathrm{C}$ for $0.5 \mathrm{~h}$ and at $70{ }^{\circ} \mathrm{C}$ for 3 days).

After the soil solution was filtered, dissolved $\mathrm{Cd}$ and $\mathrm{SO}_{4}{ }^{2-}$ levels were measured using plasma mass spectrometry and ion chromatography (861, Metrohm, Switzerland), respectively.

SOC and TN were determined by using the element analyzer (vario ISOTOPE CUBE, Elementar, Germany). DOC was calculated as mg DOC/kg soil ( $\mathrm{H}_{2} \mathrm{O}$ extraction method, Multi N/C 3100, Analytikjena, Germany $)^{45}$. Concentrations of $\mathrm{NH}_{4}{ }^{+}-\mathrm{N}$ and $\mathrm{NO}_{3}^{-}-\mathrm{N}$ were measured using a segmented-continuous flow analyzer (AutoAnalyzer 3, Bran + LUEBBE, Germany).

Plant $\mathrm{Cd}$ concentrations were determined using the procedure reported by Guo et al. via plasma mass spectrometry (PlasmaQuant MS Elite, Analytikjena, Germany) ${ }^{46}$. Calibration was applied using seven standards (e.g., $0.1,0.2,0.5,1,2,5$ and $10 \mu \mathrm{gg}^{-1}$ ). Two additional calibration standards (e.g., laver composition GBW10023, $0.57 \mathrm{mg} \mathrm{kg}^{-1}$; soil composition GBW07456, $0.59 \mathrm{mg} \mathrm{kg}^{-1}$ ) served as quality control samples for plants and soil during the plant measurement sessions. Mass fractions were calculated using linear regression equation. The obtained mass fractions for trace metals were further corrected for the respective procedural blank and recovery rate.

Real-time RT-PCR analysis of OsNramp5 and OsHMA3 expression in roots. The amplification procedure for OsNramp5, OsHMA3 and GAPDH (glyceraldehyde 3-phosphate dehydrogenase, as an internal control) was described by Chen et al. ${ }^{43}$. Details of the primers used are shown in Table S4. Each sample was run in three technical replicates. The relative expression of OsNramp5 and OsHMA3 was determined using the $2^{-\triangle \Delta C T}$ method (ABI Step One, Applied Biosystems, USA) ${ }^{47}$. 


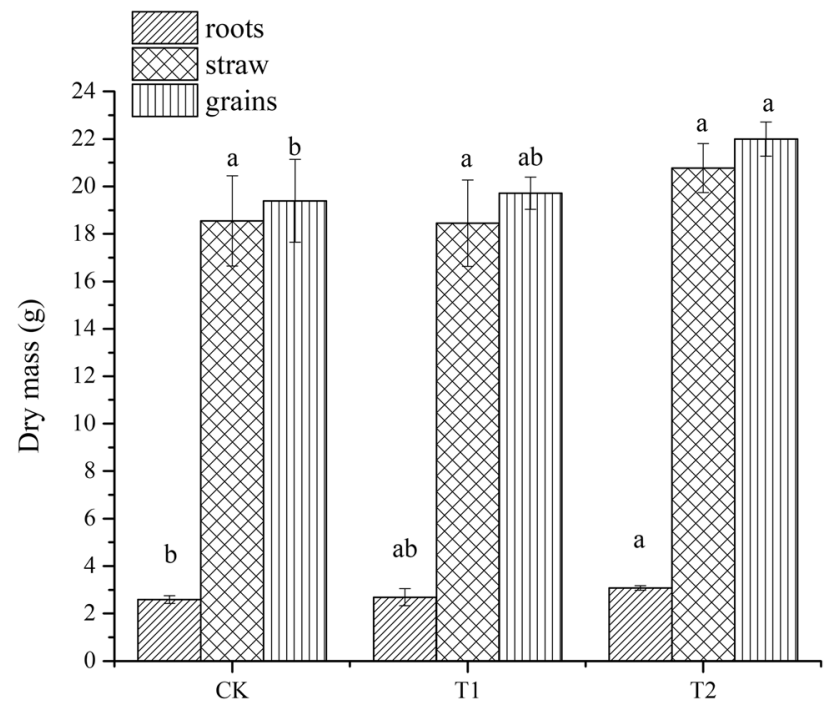

Figure 6. Roots, straw, and grains dry masses of rice. Different letters represented significant difference at $P<0.05$.

MiSeq. For each pot, three soil subsamples were collected. Total DNA in soil was extracted using an E.Z.N.A.Soil DNA Kit (Omega, USA). The V3-V4 region of the 16S rRNA gene were amplify using primers 338 F (5'-ACTCCTACGGGAGGCAGCA-3') and 806R (5'- GGACTACHVGGGTWTCTAAT-3' ${ }^{48}$. Sequencing was conducted at the Shanghai Personal Biotechnology Co., Ltd (Shanghai, China) using the Illumina MiSeq platform with a MiSeq Reagent Kit v3. A 97\% similarity of the obtained sequences was used as the criterion for the classifying of the operational taxonomic units (OTU). Alpha and beta diversities were determined using the QIIME and R packages (v3.2.0). Taxa abundances were statistically compared among samples using Metastats. A heat map was generated to show the top 50 differentially abundant genera. Principal coordinate analysis (PCoA) was performed using unweighted UniFrac distance metrics.

Statistical analysis. The translocation factor from metal accumulation (TF') was calculated as the ratio between the Cd accumulation content (mg) in aboveground plants (straw and grains) and roots. ANOVA followed by Tukey's test and correlation analysis were performed using SPSS v22.0. Significance was determined at the $P<0.05$ level. Redundancy analysis (RDA) was adopted to assess the effects of soil chemical parameters on soil microbial diversity using Canoco 5. Spearman correlation coefficients were employed to test relationships between soil properties and the relative abundance of genera using the OmicShare tools (http://www.omicshare. com/tools). All values are presented as means \pm standard deviation (s.d.).

\section{Plant material statement}

The plants adopted in this study are not threatened species or wild plants. Fresh azolla was provided by Agricultural Ecology Institute, Fujian Academy of Agricultural Sciences. Rice seeds (ZheFuJing83) were bought from market, which is a conventional rice variety in southern China. All procedure complies with relevant institutional, national, and international guidelines and legislation.

Received: 18 July 2020; Accepted: 4 March 2021

Published online: 18 March 2021

\section{References}

1. Chaney, R. L. How does contamination of rice soils with $\mathrm{Cd}$ and $\mathrm{Zn}$ cause high incidence of human $\mathrm{Cd}$ disease in subsistence rice farmers. Curr. Pollut. Rep. 1, 13-22 (2015).

2. Wang, P., Chen, H., Kopittke, P. M. \& Zhao, F. Cadmium contamination in agricultural soils of China and the impact on food safety. Environ. Pollut. 249, 1038-1048 (2019).

3. Song, Y. et al. Dietary cadmium exposure assessment among the Chinese population. PLoS ONE 12, e0177978 (2017).

4. Hu, Y., Cheng, H. \& Tao, S. The challenges and solutions for cadmium-contaminated rice in China: a critical review. Environ. Int. 92-93, 515-532 (2016)

5. Bolan, N. et al. Remediation of heavy metal(loid)s contaminated soils-To mobilize or to immobilize?. J. Hazard. Mater. 266, 141-166 (2014).

6. Khan, M. A., Khan, S., Khan, A. \& Alam, M. Soil contamination with cadmium, consequences and remediation using organic amendments. Sci. Total Environ. 601-602, 1591-1605 (2017).

7. Li, H. et al. Cadmium in rice: transport mechanisms, influencing factors, and minimizing measures. Environ. Pollut. 224, 622-630 (2017).

8. Honma, T. et al. Optimal soil Eh, $\mathrm{pH}$, and water management for simultaneously minimizing arsenic and cadmium concentrations in rice grains. Environ. Sci. Technol. 50, 4178-4185 (2016). 
9. Wang, J. et al. Iron-manganese (oxyhydro) oxides, rather than oxidation of sulfides, determine mobilization of Cd during soil drainage in paddy soil systems. Environ. Sci. Technol. 53, 2500-2508 (2019).

10. Fulda, B., Voegelin, A. \& Kretzschmar, R. Redox-controlled changes in cadmium solubility and solid-phase speciation in a paddy soil as affected by reducible sulfate and copper. Environ. Sci. Technol. 47, 12775-12783 (2013).

11. Arao, T., Kawasaki, A., Baba, K., Mori, S. \& Matsumoto, S. Effects of water management on cadmium and arsenic accumulation and dimethylarsinic acid concentrations in Japanese rice. Environ. Sci. Technol. 43, 9361-9367 (2009).

12. Zhou, H. et al. Cadmium uptake, accumulation, and remobilization in iron plaque and rice tissues at different growth stages. Ecotox. Environ. Safe. 152, 91-97 (2018).

13. Tang, W. et al. Inhibitory effects of rice residues amendment on Cd phytoavailability: a matter of Cd-organic matter interactions?. Chemosphere 186, 227-234 (2017).

14. Zhang, Q. et al. Water managements limit heavy metal accumulation in rice: dual effects of iron-plaque formation and microbial communities. Sci. Total Environ. 687, 790-799 (2019).

15. Li, H. et al. Dynamics of the rice rhizosphere microbial community under continuous and intermittent flooding treatment. J. Environ. Manag. 249, 109326 (2019).

16. Song, J. et al. Effects of $\mathrm{Cd}, \mathrm{Cu}, \mathrm{Zn}$ and their combined action on microbial biomass and bacterial community structure. Environ. Pollut. 243, 510-518 (2018).

17. Liu, H. et al. Ecological responses of soil microbial abundance and diversity to cadmium and soil properties in farmland around an enterprise-intensive region. J. Hazard. Mater. 392, 122478 (2020).

18. Muehe, E. M. et al. Rhizosphere microbial community composition affects cadmium and zinc uptake by the metal-hyperaccumulating plant Arabidopsis halleri. Appl. Environ. Microb. 81, 2173-2181 (2015).

19. Uraguchi, S. \& Fujiwara, T. Cadmium transport and tolerance in rice: perspectives for reducing grain cadmium accumulation. Rice 5, 5 (2012).

20. Uraguchi, S. et al. Low-affinity cation transporter (OsLCT1) regulates cadmium transport into rice grains. Proc. Natl. Acad. Sci. USA 108, 20959-20964 (2011).

21. Ueno, D. et al. Gene limiting cadmium accumulation in rice. Proc. Natl Acad Sci USA 107, 16500-16505 (2010).

22. Yang, X., Qin, J., Li, J., Lai, Z. \& Li, H. Upland rice intercropping with Solanum nigrum inoculated with arbuscular mycorrhizal fungi reduces grain Cd while promoting phytoremediation of Cd-contaminated soil. J. Hazard. Mater. 124325; https://doi.org/10. 1016/j.jhazmat.2020.124325 (2020).

23. Wan, Y., Huang, Q., Camara, A. Y., Wang, Q. \& Li, H. Water management impacts on the solubility of Cd, Pb, As, and Cr and their uptake by rice in two contaminated paddy soils. Chemosphere 228, 360-369 (2019).

24. Pan, Y. et al. Solubility of trace metals in two contaminated paddy soils exposed to alternating flooding and drainage. Geoderma 261, 59-69 (2016).

25. de Livera, J., McLaughlin, M. J., Hettiarachchi, G. M., Kirby, J. K. \& Beak, D. G. Cadmium solubility in paddy soils: effects of soil oxidation, metal sulfides and competitive ions. Sci. Total Environ. 409, 1489-1497 (2011).

26. Porter, S. K., Scheckel, K. G., Impellitteri, C. A. \& Ryan, J. A. Toxic metals in the environment: thermodynamic considerations for possible immobilization strategies for Pb, Cd, As, and Hg. Crit. Rev. Environ. Sci. Tecnol. 34, 495-604 (2004).

27. Shaheen, S. M., Rinklebe, J., Rupp, H. \& Meissner, R. Temporal dynamics of pore water concentrations of $\mathrm{Cd} \mathrm{Co,} \mathrm{Cu}, \mathrm{Ni}$, and $\mathrm{Zn}$ and their controlling factors in a contaminated floodplain soil assessed by undisturbed groundwater lysimeters. Environ. Pollut. 191, 223-231 (2014)

28. Yuan, C., Mosley, L. M., Fitzpatrick, R. \& Marschner, P. Amount of organic matter required to induce sulfate reduction in sulfuric material after re-flooding is affected by soil nitrate concentration. J. Environ. Manage 151, 437-442 (2015).

29. Yuan, C. et al. Cadmium solubility in paddy soil amended with organic matter, sulfate, and iron oxide in alternative watering conditions. J. Hazard. Mater. 378, 120672 (2019).

30. Meng, D. et al. Effects of redox potential on soil cadmium solubility Insight into microbial community: Insight into microbial community. J. Environ. Sci. 75, 224-232 (2019).

31. An, M. et al. Effects of polymer modifiers on the bacterial communities in cadmium-contaminated alkaline soil. Appl. Soil Ecol. 157, 103777 (2021).

32. Liu, C., Lin, H., Li, B., Dong, Y. \& Yin, T. Responses of microbial communities and metabolic activities in the rhizosphere during phytoremediation of Cd-contaminated soil. Ecotox. Environ. Safe. 202, 110958 (2020).

33. Wang, M., Duan, S., Zhou, Z. \& Chen, S. Alleviation of cadmium toxicity to tobacco (Nicotiana tabacum) by biofertilizers involves the changes of soil aggregates and bacterial communities. Ecotoxicol Environ. Safe. 169, 240-247 (2019).

34. Legg, T. M. et al. Carbon, metals, and grain size correlate with bacterial community structure in sediments of a high arsenic aquifer. Front. Microbiol. 3, 82 (2012).

35. Cabrol, L. et al. Anaerobic oxidation of methane and associated microbiome in anoxic water of Northwestern Siberian lakes. Sci. Total Environ. 736, 139588 (2020).

36. Zhou, G. et al. Rational utilization of leguminous green manure to mitigate methane emissions by influencing methanogenic and methanotrophic communities. Geoderma 361, 114071 (2020).

37. Zhou, G. et al. Non-additive responses of soil $\mathrm{C}$ and $\mathrm{N}$ to rice straw and hairy vetch (Vicia villosa Roth L.) mixtures in a paddy soil. Plant and Soil 436, 229-244 (2019).

38. Han, S. et al. Nitrospira are more sensitive than Nitrobacter to land management in acid, fertilized soils of a rapeseed-rice rotation field trial. Sci. Total Environ. 599-600, 135-144 (2017).

39. Pei, P., Sun, Y., Wang, L., Liang, X. \& Xu, Y. In-situ stabilization of Cd by sepiolite co-applied with organic amendments in contaminated soils. Ecotox. Environ. Safe. 208, 111600 (2021).

40. Yao, Y. et al. Urea deep placement in combination with Azolla for reducing nitrogen loss and improving fertilizer nitrogen recovery in rice field. Field Crop. Res. 218, 141-149 (2018).

41. Sasaki, A., Yamaji, N., Yokosho, K. \& Ma, J. Nramp5 is a major transporter responsible for manganese and cadmium uptake in rice. Plant Cell 24, 2155-2167 (2012).

42. Sasaki, A., Yamaji, N. \& Ma, J. Overexpression of OsHMA3 enhances $\mathrm{Cd}$ tolerance and expression of $\mathrm{Zn}$ transporter genes in rice. J. Exp. Bot. 65, 6013-6021 (2014).

43. Chen, X. et al. Arbuscular mycorrhizal fungi and the associated bacterial community influence the uptake of cadmium in rice. Geoderma 337, 749-757 (2019).

44. Zhang, Q. et al. The influence of liming on cadmium accumulation in rice grains via iron-reducing bacteria. Sci. Total Environ. 645, 109-118 (2018).

45. Zhan, J. et al. Characterization of dissolved organic matter in the rhizosphere of phytostabilizer Athyrium wardii (Hook.) involved in enhanced metal accumulation when exposed to $\mathrm{Cd}$ and $\mathrm{Pb}$ co-contamination. Environ. Pollut. 266, 115196 (2020).

46. Guo, B. et al. Cadmium stabilization with nursery stocks through transplantation: a new approach to phytoremediation. J. Hazard. Mater. 199-200, 233-239 (2012).

47. Han, Y., Wu, M., Hao, L. \& Yi, H. Sulfur dioxide derivatives alleviate cadmium toxicity by enhancing antioxidant defence and reducing $\mathrm{Cd}(2+)$ uptake and translocation in foxtail millet seedlings. Ecotox. Environ. Safe. 157, 207-215 (2018).

48. Ai, T. et al. A conceptual method to simultaneously inhibit methane and hydrogen sulfide production in sewers: The carbon metabolic pathway and microbial community shift. J. Environ. Manage. 246, 119-127 (2019). 


\section{Acknowledgements}

This work was supported by National Key Research and Development Program of China (No. 2017YFD0800900), National Natural Science Foundation of China (41907113), Natural Science Foundation of Zhejiang Province (LQ16D010007 and Y19D010037).

\section{Author contributions}

C. L. and B.G. wrote the main manuscript text. C.L., Y.L., H.L. and N.L. analyzed the samples and provided the data of the manuscript. G.X. supported azolla samples. Y.L. and Q.F. designed the assessment work.

\section{Competing interests}

The authors declare no competing interests.

\section{Additional information}

Supplementary Information The online version contains supplementary material available at https:/doi.org/ 10.1038/s41598-021-85648-x.

Correspondence and requests for materials should be addressed to Y.L.

Reprints and permissions information is available at www.nature.com/reprints.

Publisher's note Springer Nature remains neutral with regard to jurisdictional claims in published maps and institutional affiliations.

(c) (i) Open Access This article is licensed under a Creative Commons Attribution 4.0 International License, which permits use, sharing, adaptation, distribution and reproduction in any medium or format, as long as you give appropriate credit to the original author(s) and the source, provide a link to the Creative Commons licence, and indicate if changes were made. The images or other third party material in this article are included in the article's Creative Commons licence, unless indicated otherwise in a credit line to the material. If material is not included in the article's Creative Commons licence and your intended use is not permitted by statutory regulation or exceeds the permitted use, you will need to obtain permission directly from the copyright holder. To view a copy of this licence, visit http://creativecommons.org/licenses/by/4.0/.

(C) The Author(s) 2021 